\title{
Pityriasis lichenoides et varioliformis acuta in skin of color: new observations by dermoscopy
}

\author{
Balachandra S. Ankad ${ }^{1}$, Savitha L. Beergouder ${ }^{1}$
}

1 Department of Dermatology, S. Nijalingappa Medical College, Bagalkot, Karnataka, India

Key words: dermoscopy, pityriasis lichenoides et varioliformis acuta, diagnosis, pattern

Citation: Ankad BS, Beergouder SL. Pityriasis lichenoides et varioliformis acuta in skin of color: new observations by dermoscopy. Dermatol Pract Concept. 2017;7(1):5. DOI: http://dx.doi.org/10.5826/dpc.0701a05

Received: June 19, 2016; Accepted: October 28, 2016; Published: January 31, 2017

Copyright: @2017 Ankad et al. This is an open-access article distributed under the terms of the Creative Commons Attribution License, which permits unrestricted use, distribution, and reproduction in any medium, provided the original author and source are credited.

Funding: None.

Competing interests: The authors have no conflicts of interest to disclose.

All authors have contributed significantly to this publication.

Corresponding author: Dr. Balachandra S. Ankad, Professor, Department of Dermatology, S. Nijalingappa Medical College, Near APMC, Navanagar, Bagalkot-587103, Karnataka, India. Tel. 91 9980410056; Fax: 08354 235360. E-mail: drbsankad@gmail.com

ABSTRACT Background: Pityriasis lichenoides is an uncommon skin disease that presents in three different forms:
pityriasis lichenoides et varioliformis acuta (PLEVA), pityriasis lichenoides chronica (PLC) and febrile
ulceronecrotic-Mucha-Habermann disease. These represent a spectrum of a disease. PLEVA presents
as skin eruption of multiple, small, red papules that develop into polymorphic lesions with periods
of varying remissions, as well as possible sequels of hyper/hypopigmentation and varicella-like scars.
Diagnosis of this condition is mainly clinical, and sometimes clinical differentiation from other condi-
tions may be a difficult task that often requires histological analysis. In this study, PLEVA lesions were
examined by dermoscopy, and the significance of specific dermoscopic findings was investigated in
order to facilitate their differentiation from other inflammatory conditions.

Objectives: To evaluate dermoscopic patterns in PLEVA and to correlate these patterns with histopathology.

Materials and methods: The study was conducted at S. Nijalingappa Medical College, Bagalkot. It was an observational case series study and patients were selected randomly. Ethical clearance and informed consent were obtained. PLEVA lesions in early and late phases were evaluated. A manual DermLite 3 (3Gen, San Juan Capistrano, CA) dermoscope attached to a Sony (Cyber Shot DSC-W800, Sony Electronics Inc., San Diego, California, USA, digital, 14 mega pixels) camera was employed. Histopathology was done to confirm the diagnosis. Data was collected and analyzed. Results were statistically described in terms of frequencies and types of dermoscopic patterns.

Results: There was a total of 14 patients; 8 males and 6 females. Mean age of patients was 19 years. Mean duration of disease was 7 months. Dermoscopy in early-phase lesions revealed amorphous brownish areas around the hair follicles, dotted vessels, and scaling. Dermoscopy in late-phase lesions showed whitish-structureless areas and central white crust within whitish-structureless rim with scale, focal bluish-grayish areas or centrifugal strands irregularly distributed along the periphery and yellow structures. Red dots and hemorrhage were seen at the center and glomerular vessels at the periphery.

Conclusion: PLEVA demonstrates specific dermoscopic patterns that correlate well with histologic changes. New dermoscopic findings are described. Thus, dermoscopy is a good diagnostic tool in the clinical diagnosis of PLEVA. 


\section{Introduction}

Pityriasis lichenoides (PL), also called Mucha-Habermann disease, is characterized by multiple crusted and scaly papules. It includes three variants, namely, pityriasis lichenoides et varioliformis acuta (PLEVA), pityriasis lichenoides chronica (PLC) and febrile ulceronecrotic PLEVA. PLEVA can mimic various skin conditions such as chicken pox, lymphomatoid papulosis, guttate psoriasis, lichen planus and pityriasis rosea [1,2].

Dermoscopy is a non-invasive technique that allows a rapid and magnified in vivo observation of the skin surface. Dermoscopy is mainly utilized for the evaluation of pigmented skin lesions and has increasing applications in dermatology [3]. Here, authors evaluated dermoscopic patterns in PLEVA in brown skin, and these patterns may assist the clinical diagnosis.

\section{Objectives}

To evaluate dermoscopic patterns in PLEVA and to correlate these patterns with histopathology.

\section{Materials and Methods}

\section{PATIENTS}

This study was carried out on 14 patients attending the Department of Dermatology in a tertiary hospital attached to S. Nijalingappa Medical College at Bagalkot, southern India between March 2015 and December 2015. It was an observational case series study and patients were selected randomly. A complete history and dermatological examination were performed on patients with clinical features suggestive of PLEVA in early and late phases. The ethical clearance was obtained by the institutional ethical committee. The patients gave written informed consent. Demographic data, such as age, gender, and clinical variables in terms of site of lesions and disease duration were documented. Lesions with less than 2 months' and more than 2 months' duration were arbitrarily termed as early and late lesions. These were referred to as target lesions and were selected for dermoscopic examination. Skin biopsies were taken from target lesions to confirm the diagnosis. Same dermatologist evaluated dermoscopic patterns and was unaware of clinical diagnosis. The pathologist was also unaware of the diagnosis and same pathologist evaluated histopathological changes. Data was collected and analyzed. The results were statistically described as types of dermoscopic patterns.

\section{DERMOSCOPIC EXAMINATION}

A DermLite 3 dermoscope (10x magnification) with both polarized and non-polarized lights was employed in the study. A Sony camera was attached to save the images. Initially, ultrasound gel was applied either on the faceplate of the dermoscope or on the skin lesion and then lesions were observed through the eyepiece of the dermoscope. However, only the polarized light version was used in our study to appreciate color patterns in the dermis. Although polarized dermoscopy was employed, ultrasound gel was applied for clarity of images and to lessen distortions associated with light [4]. Care was taken in holding the dermoscope a little above the surface of skin lesions to visualize the vascular structures [5].

\section{Inclusion criteria:}

1. Patients with signs and symptoms of PLEVA [6],

2. Patients with PLEVA lesions in both early and late phases were included.

3. Patients who had not received or stopped treatment for PLEVA one month prior to the study.

\section{Exclusion criteria:}

1. Patients with secondary infection superseding PLEVA.

2. Patients who were receiving treatment one month prior to the study.

\section{Results}

There were 14 patients ( 8 male, 6 female) in the study. The patients with PLEVA with mean duration of disease of 7 months [minimum 2 months and maximum 12 months] and mean age of 19 years presented with acute onset of erythematous papules with hemorrhagic crusting. Two (14.28\%) and $12(85.71 \%)$ patients had early (Figure 1$)$ and late (Figure 2$)$ lesions of PLEVA respectively.

Dermoscopy of early phase lesions: It showed amorphous brownish area around the hair follicles and rim of scale in the center and dotted vessels at periphery (Figure 3).

Dermoscopy of late phase lesions: It demonstrated whitishstructureless areas arranged in a haphazard pattern with vague

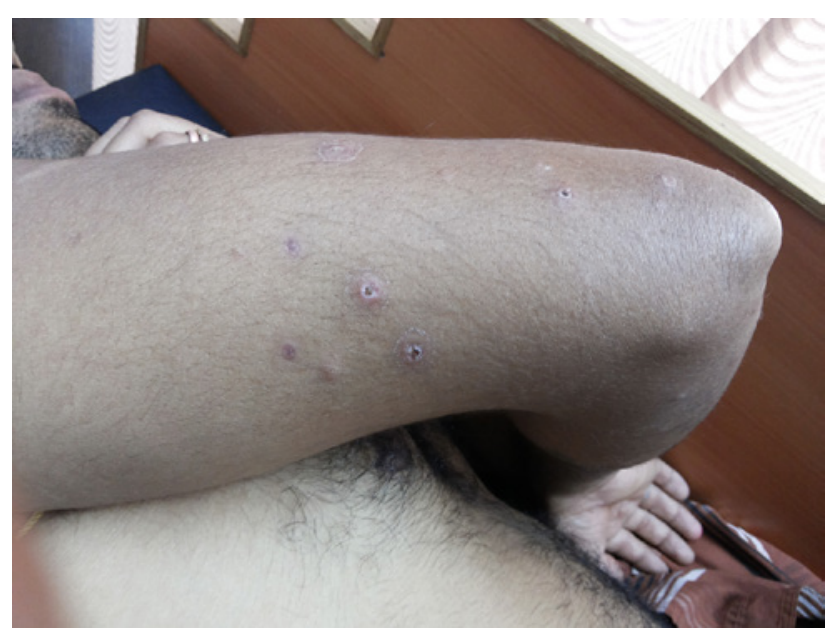

Figure 1. Clinical image of pityriasis lichenoides et varioliformis acuta with excoriated papules with crust. [Copyright: @2017 Ankad et al.] 


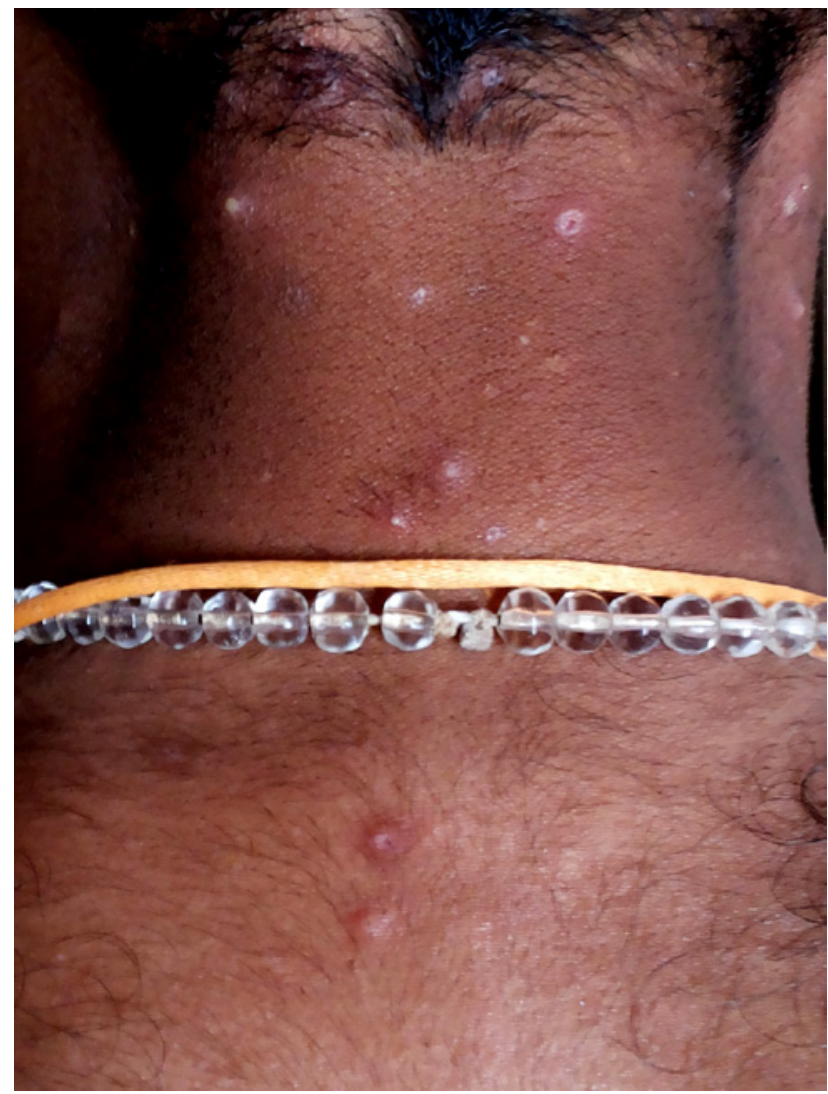

Figure 2. Clinical image of pityriasis lichenoides et varioliformis acuta with erythematous papules and pustules with crust. [Copyright: @2017 Ankad et al.]

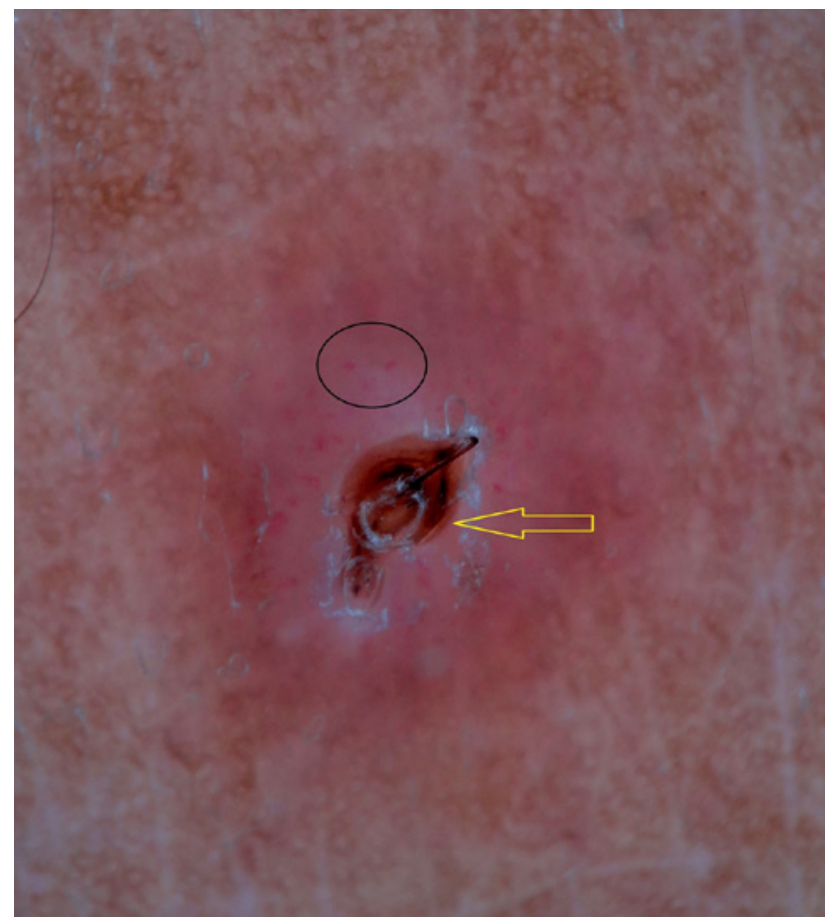

Figure 3. Dermoscopy pityriasis lichenoides et varioliformis acuta showing amorphous brownish area (yellow arrow) around the hair follicles and dotted vessels (black circle) and rim of scale. [Copyright: @2017 Ankad et al.]

glomerular and dotted vessels in the periphery (Figure 4), central white crust and whitish-structureless rim with scale, focal

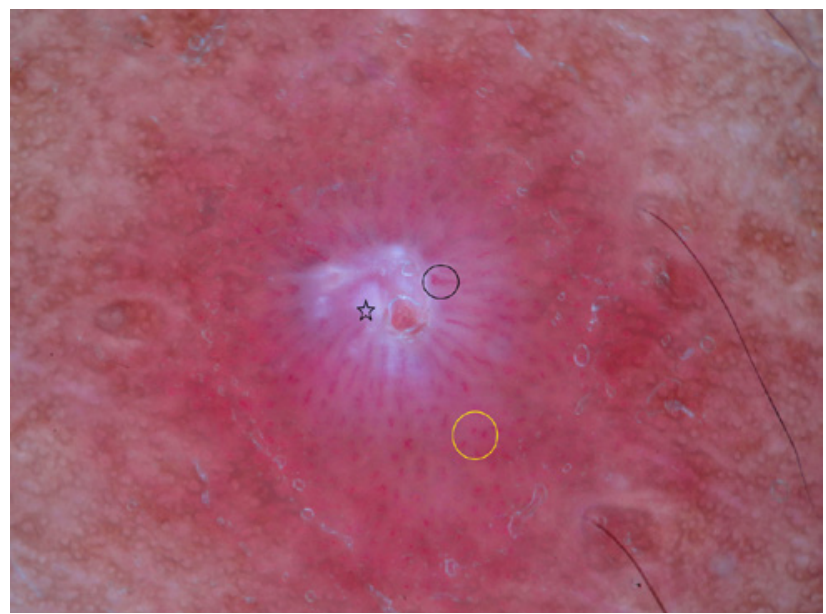

Figure 4. Dermoscopy showed whitish structureless areas (black star) arranged in a haphazard pattern with vague glomerular (black circle) and dotted (yellow circle) vessels in the periphery. [Copyright: (C)2017 Ankad et al.]

bluish-grayish areas or centrifugal strands irregularly distributed along the periphery, and yellow structures and red dots and hemorrhage within the central crust-plug (Figures 5, 6).

Histopathological examination showed hyperkeratosis, epidermal ulceration with basophilic infiltration, vacuolar alteration of basal layer, necrotic keratinocytes, and pronounced lymphocytic infiltrate in the papillary dermis in wedge-shaped pattern along with perivascular infiltration in early phase (Figure 7). In late lesions, hyperkeratosis, acanthosis, erosion in the epidermis, basal cell degeneration and lymphocytic infiltrate around capillaries were seen (Figure 8) [7]. Dilatation of dermal capillaries was observed in both phases.

Frequencies of various dermoscopic patterns are presented in Table 1, and corresponding histopathological changes are depicted in Table 2.

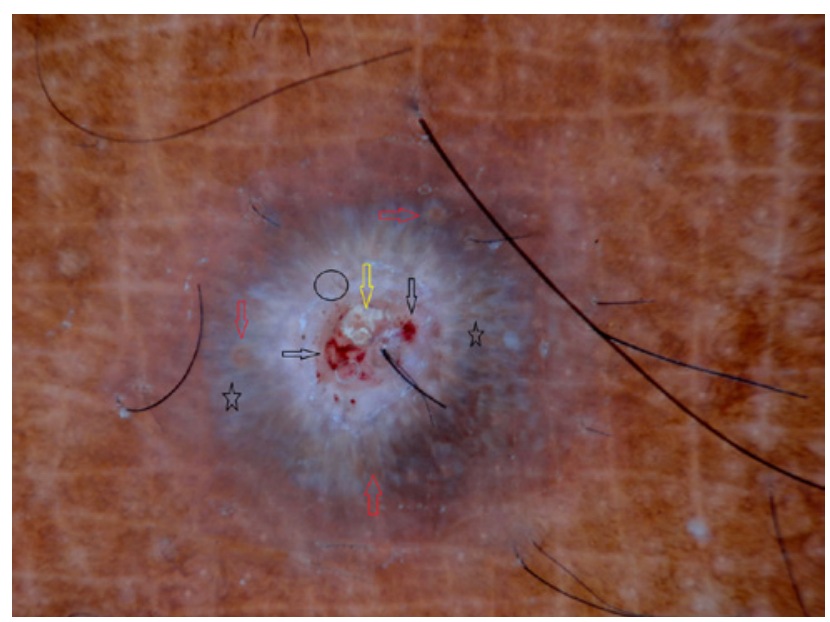

Figure 5. Dermoscopy of pityriasis lichenoides et varioliformis acuta showing whitish-yellow structureless rim white scale (black circle), whitish crust in the centre (yellow arrow), focal bluish-grayish areas (black stars). Red dots and hemorrhage within the central crust-plug (black arrows). [Copyright: @2017 Ankad et al.] 


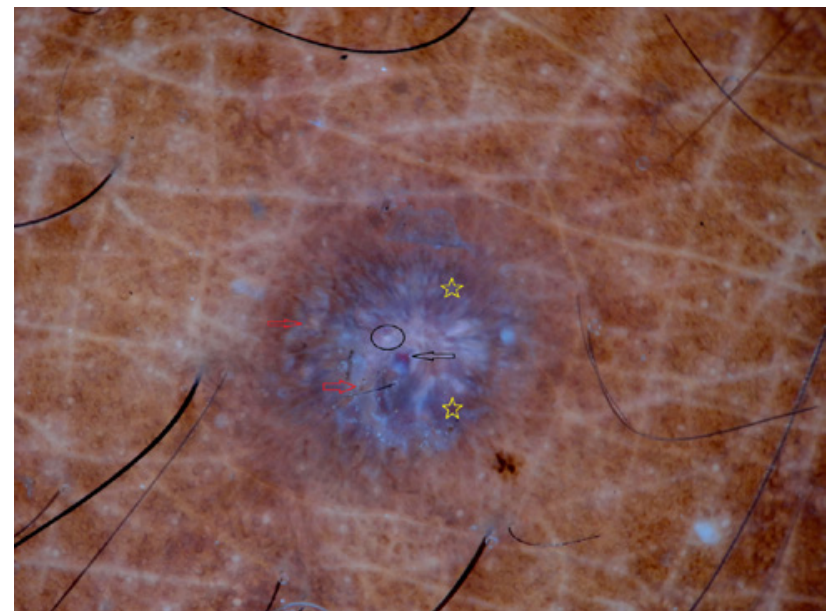

Figure 6. Dermoscopy of pityriasis lichenoides et varioliformis acuta showing whitish-yellow structureless areas (black circle), focal bluish-grayish areas (yellow stars), hemorrhage (black arrow) and scale.

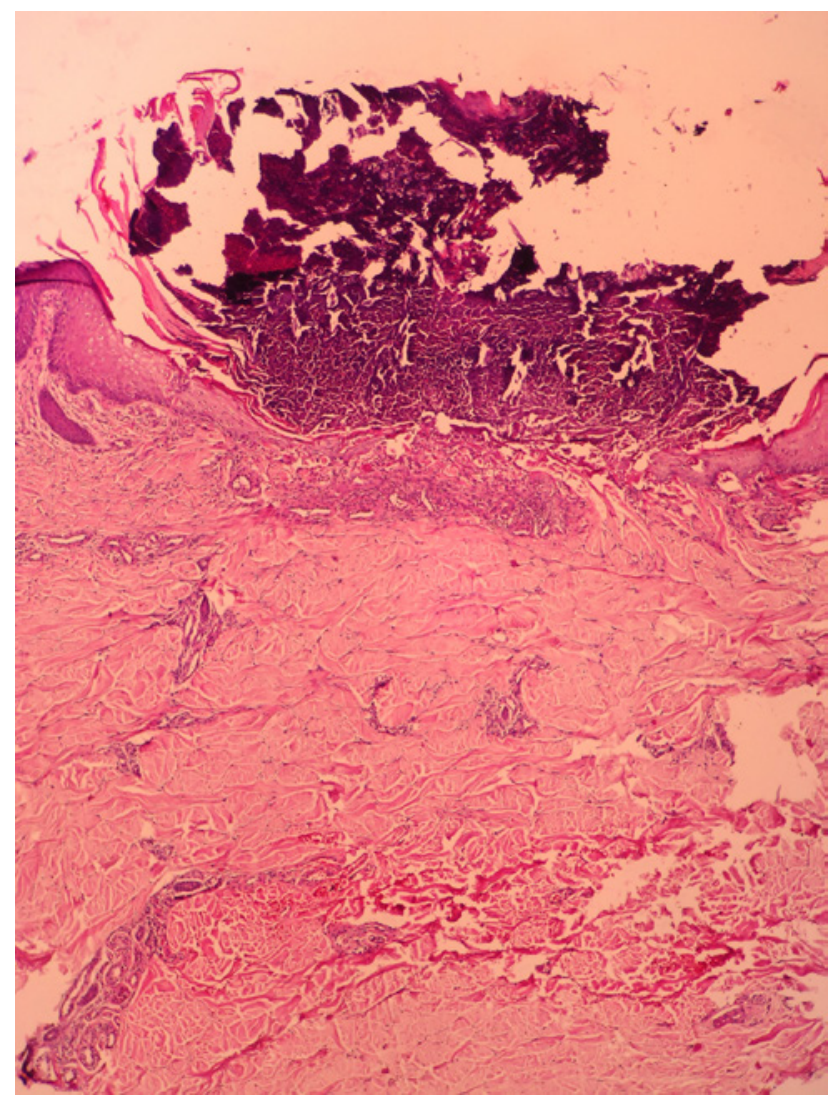

Figure 7. Histopathology in early phase shows hyperkeratosis, epidermal ulceration with basophilic infiltration, vacuolar alteration of basal layer, necrotic keratinocytes and pronounced lymphocytic infiltrate in the papillary dermis in wedge shaped pattern along with perivascular infiltration and dilatation of dermal capillaries is seen (H\&E, 10 x). [Copyright: @2017 Ankad et al.]

\section{Discussion}

PLEVA presents with a skin eruption of multiple, small, red papules that develop into polymorphic lesions and vacillates with periods of varying remissions as well as possible sequels of hyper/hypopigmentation and varicella-like scars. PLEVA is mainly diagnosed clinically, but sometimes it poses a great

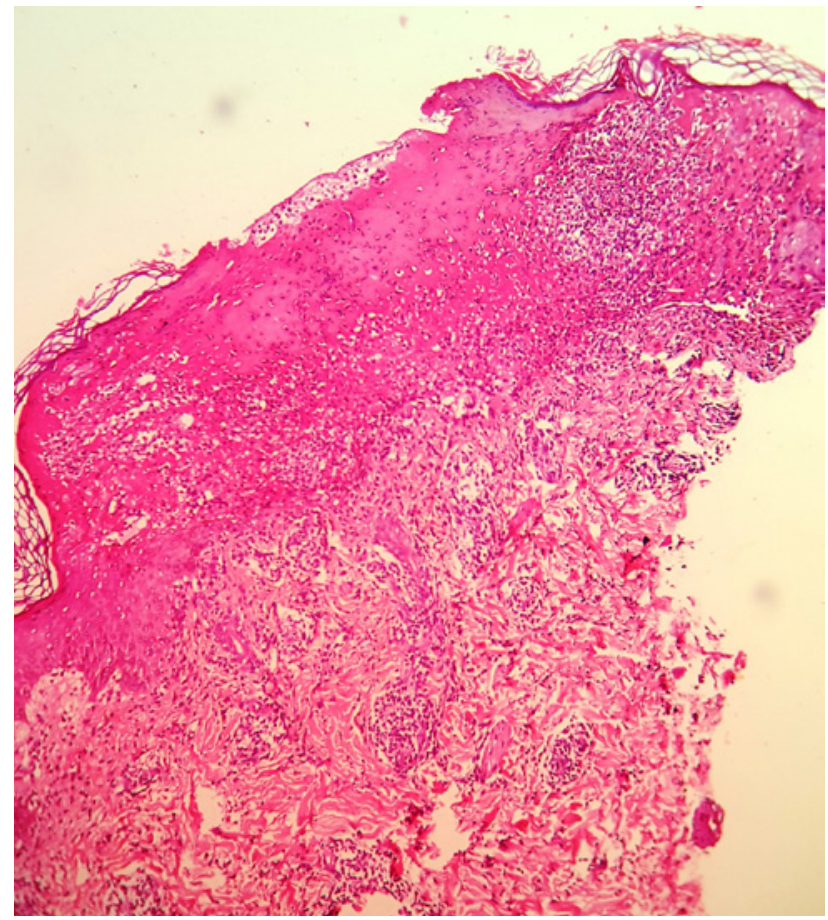

Figure 8. Histopathology in late phase shows hyperkeratosis, acanthosis, erosion in the epidermis, basal cell degeneration and lymphocytic infiltrate around capillaries with dilatation of blood vessels (H\&E, 10 x). [Copyright: @2017 Ankad et al.]

challenge to differentiate it from common conditions like chicken pox, guttate psoriasis, Gianotti-Crosti syndrome, lichen planus and pityriasis rosea, and in such situations histopathology helps to confirm the diagnosis [1].

Dermoscopy is a novel diagnostic technique; beside its traditional use in melanoma detection, it is being used more and more in the assessment of other general dermatologic conditions, namely scalp and hair disorders (trichoscopy), nails abnormalities (onychoscopy), skin infections and infestations (entomodermoscopy), and cutaneous inflammatory diseases (inflammoscopy) [3]. In this study, authors evaluated dermoscopic patterns in PLEVA.

In this study, dermoscopy of early PLEVA lesions i.e., lesions aged less than 2 months revealed an amorphous brownish area around the hair follicles within a rim of white scale and dotted vessels at the periphery. In a study of dermoscopy of PLEVA by Lacarrubba et al, the authors observed an amorphous brownish structure and a ring of pinpoint and linear vessels in a "targetoid" pattern surrounding whitish-structureless areas [8]. Similar findings were observed in this study. However, the targetoid pattern of vessels was not observed. Vessels were in dotted pattern at the periphery. These correspond to microhemorrhages and extravasations of red blood cells in the papillary dermis. This disparity may be the result of the early stage of lesions and the dermoscopic technique followed in this study. Interestingly, an amorphous brownish structure was noted around the hair follicle. This finding was not mentioned in the previous study. 
TABLE 1. Dermoscopic patterns and their frequency. [Copyright: @2017 Ankad et al.]

\begin{tabular}{|c|c|c|}
\hline SI. No. & Dermoscopic patterns & $\begin{array}{l}\text { Frequency } \\
(n=14), n(\%)\end{array}$ \\
\hline 01 & $\begin{array}{l}\text { White structures } \\
\text { - Whitish-structureless areas in haphazard pattern } \\
\text { - Whitish-structureless rim with central crust-plug }\end{array}$ & $\begin{array}{r}2(14.28) \\
10(85.71)\end{array}$ \\
\hline 02 & $\begin{array}{l}\text { Red structures } \\
\text { - Dotted vessels } \\
\text { - Hemorrhages } \\
\text { - Vague glomerular }\end{array}$ & $\begin{array}{l}8(57.14) \\
4(28.57) \\
2(14.28)\end{array}$ \\
\hline 03 & Focal bluish-grayish areas & $10(71.42)$ \\
\hline 04 & Yellow globules or structures & $10(71.42)$ \\
\hline 05 & Amorphous brownish areas & $2(14.28)$ \\
\hline 06 & Scaling & $8(57.14)$ \\
\hline
\end{tabular}

TABLE 2. Dermoscopic patterns and corresponding histopathological changes. [Copyright: (O2017 Ankad et al.]

\begin{tabular}{|c|l|l|}
\hline SI No. & \multicolumn{1}{|c|}{ Dermoscopic patterns } & \multicolumn{1}{|c|}{ Corresponding histopathologic changes } \\
\hline 01 & Whitish-structureless areas & Hyperkeratosis and acanthosis \\
\hline 02 & Whitish-structureless rim with central crust-plug & Hyperkeratosis and epidermal erosion \\
\hline 03 & Red dots and hemorrhage & $\begin{array}{l}\text { Microhemorrhages and extravasations of red blood cells in } \\
\text { the papillary dermis and dilatation of blood vessels }\end{array}$ \\
\hline 04 & Vague glomerular vessels & Dilatation of blood vessels \\
\hline 05 & Focal bluish-grayish areas & Melanin pigment in the dermis \\
\hline 06 & Yellow globules or structures & Spongiosis and basal cell degeneration \\
\hline 07 & Amorphous brownish areas & $\begin{array}{l}\text { Crust-plug with basophilic material in epidermis and } \\
\text { lymphocytic infiltrate in the dermis }\end{array}$ \\
\hline 08 & Scaling & Hyperkeratosis \\
\hline
\end{tabular}

An amorphous brownish structure corresponds to a central crust consisting of basophilic material in the epidermis and wedge-shaped lymphocytic infiltrate in the dermis.

Late-phase lesions demonstrated whitish-structureless areas and a central crust-plug surrounded by whitish rim with scale. This is in correlation with previous observation [8]. Red dots and hemorrahges were observed in the center, within the whitish rim. Whitish-structureless areas are seen in inflammatory conditions such as prurigo nodularis, hypertrophic lichen planus, and morphea and in some of the non-melanocytic skin tumors [9-13]. In hypertrophic lichen planus and prurigo nodularis it is referred to as pearly white structure spread over the entire lesion and seen characteristically in a "starburst" pattern in prurigo nodularis; and in hypertrophic lichen planus it is distributed diffusely in the centre $[9,10]$. In morphea, it appears as whitish strands with dilated blood vessels [11]. In non-melanocytic tumors, white structures are arranged in a specific pattern, which give a supportive clue to the clinical diagnosis. In dermatofibroma, it takes on the "starburst" pattern [12], and in eccrine spiradenoma, it is arranged as structureless areas surrounding serpentine vessels [13]. Histopathological correlation of white structures under dermoscopy depends on the condition. For example, it suggests hyperkeratosis, acanthosis and dermal fibrosis in hypertrophic lichen planus and prurigo nodularis; in morphea, eccrine spiradenoma and dermatofibroma it indicates increased collagen in the dermis. In PLEVA, it represents hyperkeratosis. Thus pattern of whitish-structureless areas gives a clue to the clinical diagnosis.

Focal bluish-grayish areas or strands distributed peripherally were observed in late lesions. This finding is not reported in the previous study. The authors believe that this finding is due to scratching and skin of color. The configurations and patterns of focal bluish-grayish areas are specific for each condition. They are discrete, ovoid nests pattern in pigmented and superficial types of basal cell carcinoma [14]. In hyper- 


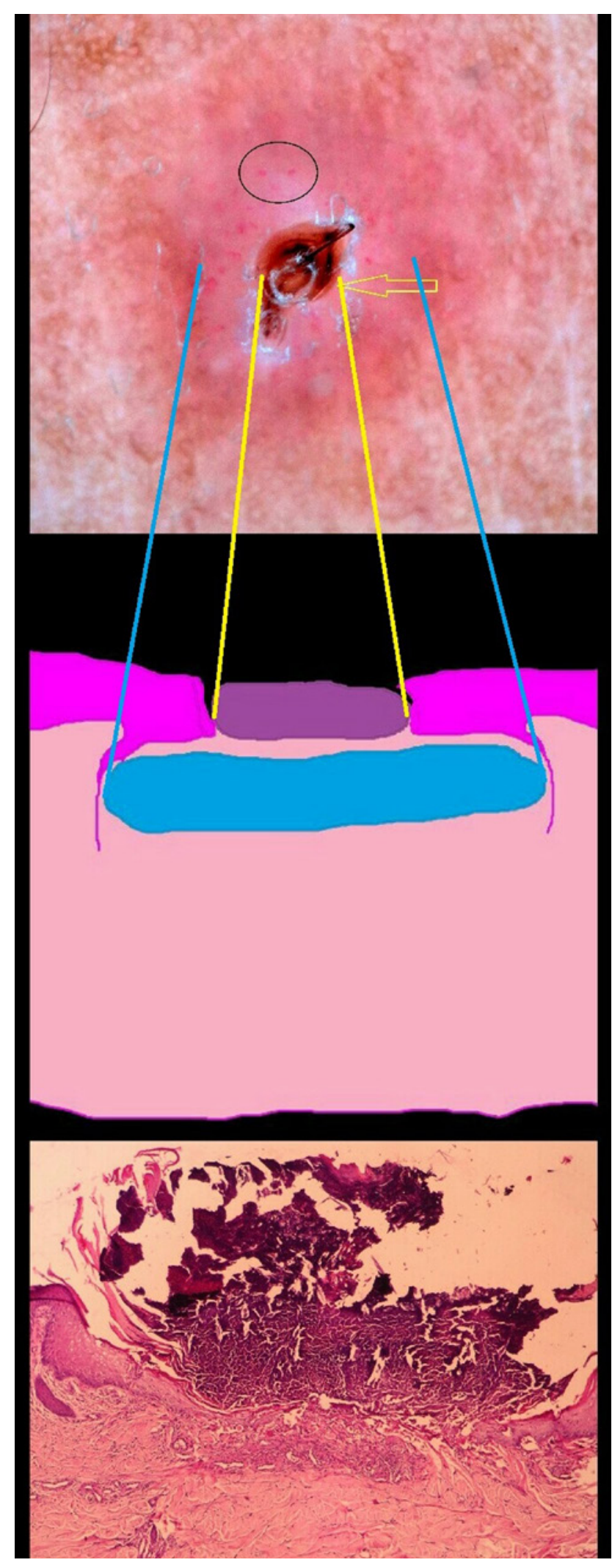

Figure 9. Image depicting correlation of dermoscopic patterns with histopathological changes in early phase of pityriasis lichenoides et varioliformis acuta. [Copyright: (O2017 Ankad et al.]

trophic lichen planus, they are distributed centrifugally within pearly white areas [10]. In PLEVA, too, focal bluish-grayish areas were seen interspersed within whitish-structureless areas. Thus, arrangement of focal bluish-grayish areas is useful clue to support the clinical diagnosis.

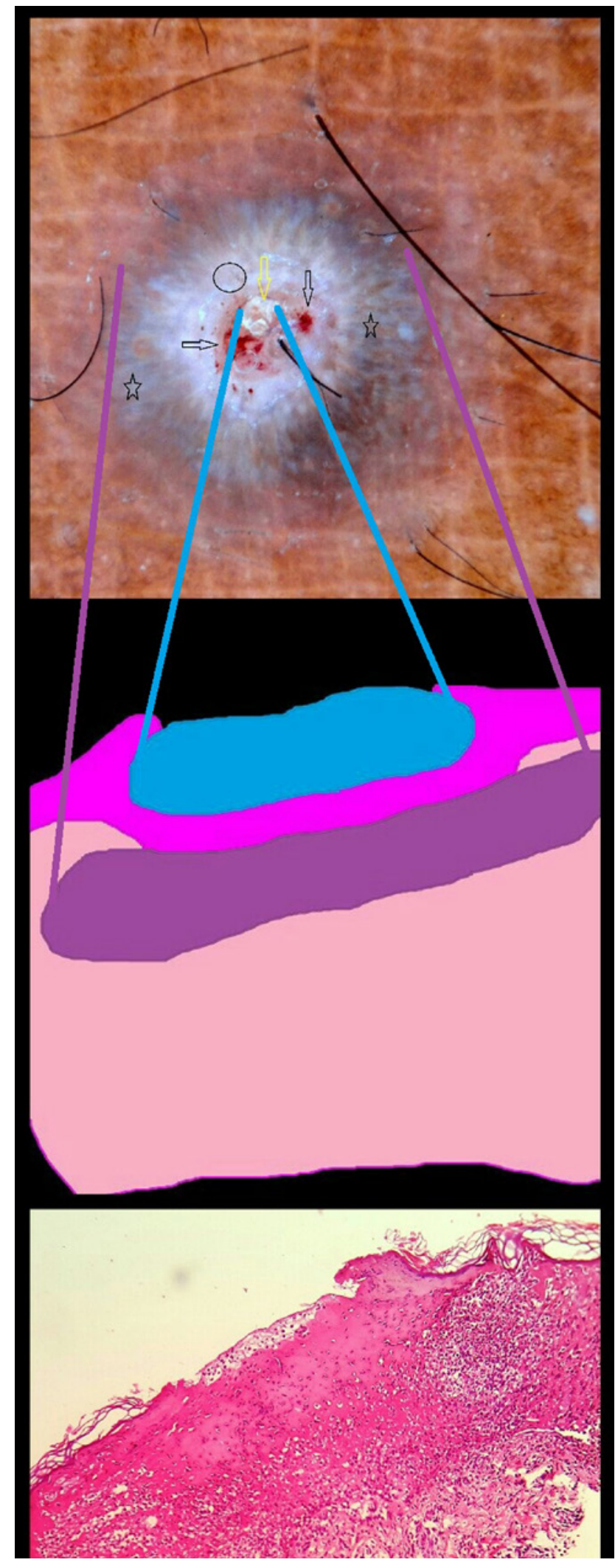

Figure 10. Image depicting correlation of dermoscopic patterns with histopathological changes in late phase of pityriasis lichenoides et varioliformis acuta. [Copyright: (92017 Ankad et al.]

Yellow structures were arranged diffusely within focal bluish-grayish areas and whitish structureless areas. These were not described in PLEVA. However, orange-yellowish structureless areas were observed in dermoscopic examination of pityriasis lichenoides chronica by Errichetti et al. Orange-yellowish 
structureless areas correspond to hemosiderin deposition in the dermis [16]. In this study, the orange hue was absent and only the yellowish color was appreciated. Hence, the authors propose that yellow structures in PLEVA are produced as a result of the increased duration of lesions and that they represent spongiosis and basal cell degeneration on histology. Yellow structures noted in hypertrophic lichen planus correspond to spongiosis and basal cell degeneration [10, 15]. In hypertrophic lichen planus, yellow structures are arranged in a "lacy network" pattern [10] and in dermatitis, they are in a diffuse pattern, giving rise to the "yellow clod" sign [17].

Red dots and hemorrhages represent focal hemorrhage and dilated vessels in the papillary dermis. The types of vessels and their arrangement form an important factor in the clinical diagnosis by dermoscopy. In this study, red dots and hemorrhage were situated in the center and vague glomerular and dotted vessels at the periphery. In the previous study of dermoscopy of PLEVA, the authors observed a ring of pinpoint and linear vessels in a "targetoid" pattern surrounding whitish-structureless areas [8]. In inflammatory conditions, vessels are distributed and arranged in a specific pattern, which aids in an accurate diagnosis. In psoriasis, red dots are diffuse in a regularly arranged pattern on an erythematous background. In pityriasis rosea, they are distributed in an irregular or patchy manner at the periphery on a yellowish base. The cluster pattern of vessels is characteristic in all types of dermatitis [17]. In seborrheic keratosis and clear cell carcinoma, vessels are in "hair-pin" and "string of pearls" patterns respectively [18]. In pityriasis lichenoides chronica, milky red areas/globules, linear irregular and branching vessels are seen [16]. Hence, the pattern of blood vessels is of diagnostic importance in the dermoscopic studies.

In the present study, the authors noted focal bluishgrayish areas and yellow structures, which are not described in literature. The authors believe that the duration of lesions, scratching, and skin of color attribute to focal bluish-grayish areas and yellow structures. PLEVA lesions in the early phase showed an amorphous brownish area that correlated with basophilic material and wedge-shaped lymphocytic infiltrate on histology (Figure 9), whereas late-phase lesions demonstrated whitish structureless areas, focal bluish-grayish areas, and yellow structures corresponding to epidermal erosion, hyperkeratosis, spongiosis, basal cell degeneration in infiltrate on histology (Figure 10). However, limitations in this method do exist, and they include usage of ultrasound gel in polarized version of dermoscopy, the small study sample, and in that the same dermatologist performed dermoscopic evaluation all PLEVA lesions.

\section{Conclusion}

PLEVA is a rare disorder that can be challenging to differentiate clinically from a number of common dermatoses, and hence require skin biopsy. Dermoscopy is a simple diagnostic tool that helps in the diagnosis of PLEVA with specific and characteristic patterns that correlate well with histopathological changes. New dermoscopic findings of PLEVA are described here. However, this study was performed on a limited number of patients, and hence, further studies are warranted to elucidate these findings.

Acknowledgements: The authors wish to acknowledge the help of Dr. Vijay Domble for his assistance with histopathology.

\section{References}

1. Perrin BS, Yan AC, Treat JR. Febrile ulceronecrotic MuchaHabermann disease in a 34-month-old boy: a case report and review of the literature. Paediatric Dermatol. 2012;29(1):53-58.

2. Khachemoune A, Blyumin ML. Pityriasis lichenoides: pathophysiology, classification, and treatment. Am J Clin Dermatol. 2007;8(1):29-36.

3. Errichetti E, Stinco G. The practical usefulness of dermoscopy in general dermatology. G Ital Dermatol Venereol. 2015;150(5):533546.

4. Bowling J. Introduction to dermoscopy. In: Bowling J, ed. Diagnostic Dermoscopy: The Illustrated Guide. 1st ed. West Sussex: Wiley-Blackwell; 2012:2-14.

5. Kreusch J. How to perform dermoscopy of non-pigmented skin lesions. In: Zalaudek I, Argenziano G, Giacomel J, eds. Dermatoscopy of Non-Pigmented Skin Tumors: Pink - Think - Blink. New York: CRC Press; 2016:17-18.

6. James WD, Elston DM, Neahaus IM, eds. Cutaneous lymphoid hyperplasia, cutaneous T-cell lymphoma, other malignant and other allied disorders. In: Andrew's Diseases of the Skin-Clinical Dermatology. 12 ${ }^{\text {th }}$ ed. Philadelphia: Elsevier; 2016:726-746.

7. Mobini N, Caire ST, Hu S, Kamino H. Noninfectious erythematous, papular, and squamous diseases. In: Elder DE, Elenitsas, Rosenbach M, Murphy GF, Rubin AI, Xu X, eds. Lever's Histopathology of the Skin. $11^{\text {th }}$ ed. Philadelphia: Wolters Kluwer; 2015:192-239.

8. Lacarrubba F, Micali G. Dermoscopy of pityriasis lichenoides et varioliformis acuta. Arch Dermatol. 2010;146(11):1322.

9. Errichetti E, Piccirillo A, Stinco G. Dermoscopy of prurigo nodularis. J Dermatol. 2015;42:632-634.

10. Ankad BS, Beergouder SL. Hypertrophic lichen planus versus prurigo nodularis: a dermoscopic perspective. Dermatol Pract Concept. 2016;6(2):9-15.

11. Shim WH, Jwa SW, Song M, et al. Diagnostic usefulness of dermatoscopy in differentiating lichen sclerosus et atrophicus from morphea. J Am Acad Dermatol. 2012;66:690-691.

12. Johr RH, Stolz W. Dermoscopy from A to Z. In: Johr RH, Stolz W, eds. Dermoscopy-An Illustrated Self-Assessment Guide. New York: McGraw Hill; 2010:1-26.

13. Ankad BS, Beergouder SL, Domble V, Sujana L. A serpentine inside eccrine spiradenoma: A new trichoscopic sign. Int J Trichol. 2015;7:38-40. PMID: 25878450

14. Scalvenzi, M, Lembo S, Francia MG, Balato A. Dermoscopic patterns of superficial basal cell carcinoma. Int J Dermatol. 2008;47:1015-1018.

15. Doshi B, Khopkar U. Histopathology of lichen planus and its variants. In: Khopkar U, Valia A, eds. Lichen Planus. New Delhi: Jaypee Brothers Medical Publisher (P) Ltd; 2013:123-147. 
16. Errichetti E, Lacarrubba F, Micali G, Piccirillo A, Stincol G. Differentiation of pityriasis lichenoides chronica from guttate psoriasis by dermoscopy. Clin Exp Dermatol. 2015;40:804-806.

17. Lallas A, Kyrgidis A, Tzellos TG, Apalla Z, et al. Accuracy of dermoscopic criteria for the diagnosis of psoriasis, dermatitis, lichen planus and pityriasis rosea. Br J Dermatol. 2012;166:1198-1205.

18. Bowling J. Non-melanocytic lesions. In: Bowling J, ed. Diagnostic Dermoscopy: The Illustrated Guide. 1st ed. West Sussex: WileyBlackwell; 2012:59-91. 